\title{
ESTUDO ANATÔMICO DO LENHO DE CALLISTHENE INUNDATA BUENO, NILSON \& MAGALHÃES ${ }^{1}$
}

\author{
ANELISE MARTA SIEGLOCH ${ }^{2}$ SIDINEI RODRIGUES DOS SANTOS ${ }^{3}$ \\ JOSÉ NEWTON CARDOSO MARCHIORI ${ }^{4}$
}

\section{RESUMO}

O lenho de Callisthene inundata é anatomicamente descrito. Os detalhes microscópicos são comparados com referências da literatura, destacando-se: poros solitários e em múltiplos radiais, placas de perfuração simples, raios curtos, parênquima axial em faixas e fibras septadas.

Palavras-chave: Anatomia da Madeira, Callisthene inundata, Vochysiaceae.

\section{ABSTRACT}

[Wood anatomy of Callisthene inundata Bueno, Nilson \& Magalhães].

The wood of Callisthene inundata is anatomically described. The microscopic features are compared with literature references, being pointed out: solitary and radial multiple pores, simple perforation plates, short rays, axial parenchyma in large bands, and septate wood fibers.

Key words: Wood Anatomy, Callisthene inundata, Vochysiaceae.

\section{INTRODUÇÃO}

Com exceção de Erismadelphus, gênero da África tropical ocidental, a família Vochysiaceae compreende 5 gêneros americanos que estão bem representados na flora brasileira e tem como centros de diversidade as regiões Guiano-Amazônica, o Planalto Central e a Floresta Atlântica: Erisma, Callisthene, Qualea, Salvertia e Vochysia (Quirk, 1980; Viana, 2006).

O gênero Callisthene Mart. reúne 12 espécies brasileiras, distribuídas, principalmente, em cerrados, cerradões e campos do Planalto Central, nos estados de Goiás e Minas Gerais (Bueno et al., 2000). Aparentemente endêmica no Rio Grande do Sul, Callisthene inundata Bueno,

1 Recebido para publicação em 14/06/2011 e aceito para publicação em 30/06/2011.

2 Engenheira Florestal, formada pela Universidade Federal de Santa Maria. Santa Maria, RS, Brasil. anesiegloch@yahoo.com.br

3 Biólogo, bolsista ( $\mathrm{CNPq}$ - Brasil), doutorando do Programa de Pós-Graduação em Engenharia Florestal, Departamento de Ciências Florestais, Universidade Federal de Santa Maria, CEP 97105-900, Santa Maria, RS, Brasil.sthurt.bio@gmail.com

${ }^{4}$ Engenheiro Florestal, Dr. Bolsista de Produtividade em Pesquisa (CNPq - Brasil). Professor Titular do Departamento de Ciências Florestais, Universidade Federal de Santa Maria. Santa Maria, RS, Brasil.
Nilson \& Magalhães é a única espécie nativa no Estado (Sobral et al., 2006).

Com distribuição restrita à bacia TaquariAntas, nas regiões fisiográficas das Encostas Superior e Inferior do Nordeste, Callisthene inundata habita solos rasos e inundáveis da mata ripária (Bueno et al., 2000). Trata-se de árvore de 7-10 m de altura, com tronco retorcido, engrossado próximo ao solo, e ramos flexíveis, inermes, de crescimento limitado, que se parecem a folhas compostas. Estas, simples, opostas e elíptico-lanceoladas (4 - 6 × 0,6 - 1,5 cm), apresentam ápice acuminado, glandulosomucronado, base arredondada e pecíolo de $1 \mathrm{~mm}$ de comprimento. As flores, axilares, solitárias e zigomorfas, são pequenas $(10 \mathrm{~mm})$, amarelocremes, e os frutos capsulares (Bueno et al. 2000; Sobral et al., 2006).

Embora sem madeira de valor comercial, devido ao diâmetro reduzido dos troncos, Callisthene inundata indica-se para a recuperação de matas ciliares degradadas e obras de Bioengenharia, por suportar ambientes inundáveis e solos rasos. Único representante lenhoso da família na flora sulrio-grandense, o presente estudo também visa a contribuir para o conhecimento anatômico das Vochysiaceae no sul do Brasil. 


\section{REVISÃO DE LITERATURA}

Recentemente descrita, Callisthene inundata carece de estudo anatômico-estrutural do lenho.

Para o conjunto das Vochysiaceae, Quirk (1980) reconheceu caracteres diagnósticos para separação de gêneros, relacionando para Callisthene os seguintes aspectos anatômicos, com base em 8 espécies do sudeste do Brasil, áreas de Caatinga, norte do Paraguai e leste da Bolívia: vasos curtos e de pequeno diâmetro, geralmente solitários, em curtos múltiplos radiais (2-4) e com poucas unidades $/ \mathrm{mm}^{2}$; pontoações intervasculares pequenas; parênquima paratraqueal escasso, vasicêntrico incompleto ou apotraqueal em faixas de 2-5 células; raios heterogêneos, extremamente numerosos e geralmente multisseriados, com $480 \mu \mathrm{m}$ e até 22 células de altura, por 3-4 células de largura; fibras septadas; e cristais presentes em células de raio e parênquima axial.

Para a família, Record \& Hess (1942) referem: anéis de crescimento visíveis ou não; poros de diâmetro médio a grande, pouco frequentes a numerosos, solitários ou em curtos múltiplos radiais, sem padrão definido de distribuição, mas tendendo, por vezes, a arranjo diagonal; placas de perfuração simples; espessamentos espiralados, ausentes; pontoações intervasculares alternas, de diâmetro médio e ornamentadas; parênquima abundante, paratraqueal aliforme, frequientemente confluente ou em largas faixas; raios pequenos a médios; fibras de parede fina a espessa, com pequenas pontoações simples; e canais de goma presentes em três gêneros.

Outros trabalhos anatômicos relevantes para a família Vochysiaceae encontram-se em Metcalfe \& Chalk (1972), Mattos et al. (2003) e Barros et al. (2003).

\section{MATERIAL E MÉTODOS}

O material em estudo consiste de uma amostra de madeira e respectivo material botânico, procedente do Rio Grande do Sul. Anexado ao Herbário do Departamento de Ciências Florestais (HDCF) da Universidade Federal de Santa
Maria sob número 6093, constam na respectiva etiqueta os seguintes registros: Marchiori, J.N.C., n. 986; mata ciliar (reófila) do rio das Antas; estrada RS 448 (Farroupilha-Nova Roma do Sul); 31/02/2009.

Para a confecção das lâminas histológicas foram extraídos três corpos de prova $(1 \times 2 \times 3 \mathrm{~cm})$ da parte mais externa do lenho, próxima ao câmbio, orientados para obtenção de cortes nos planos transversal, longitudinal radial e longitudinal tangencial. Outro bloquinho foi também retirado, com vistas à maceração.

A confecção das lâminas histológicas seguiu a metodologia descrita em Burger \& Richter (1991). As lâminas de macerado foram obtidas de acordo com o método de Jeffrey (Freund, 1970). Os cortes anatômicos foram tingidos com acridina-vermelha, crisoidina e azul-de-astra (Dujardin, 1964); o macerado, apenas com safranina (1\%). Na montagem de lâminas permanentes, usou-se Entellan.

A descrição baseou-se nas recomendações do IAWA Committee (Wheeler et al., 1989). No caso da percentagem dos tecidos foram realizadas 600 determinações ao acaso com auxílio de contador de laboratório, conforme proposto por Marchiori (1980). A freqüência de poros foi obtida a partir de um quadrado de área conhecida, superposto a fotomicrografias de seções transversais da madeira.

As medições foram realizadas em microscópio Carl Zeiss, no Laboratório de Anatomia da Madeira da Universidade Federal de Santa Maria. Nas características quantitativas, os números entre parênteses equivalem aos valores mínimos e máximos observados; o valor que acompanha a média é o desvio padrão. As fotomicrografias foram tomadas em microscópio Olympus CX40, equipado com câmera digital Olympus Camedia c3000, no Laboratório de Anatomia da Madeira da Universidade Federal do Paraná, a quem os autores agradecem.

\section{DESCRIÇÃO ANATÔMICA}

Madeira de porosidade difusa. Anéis de crescimento pouco distintos, delimitados por del- 

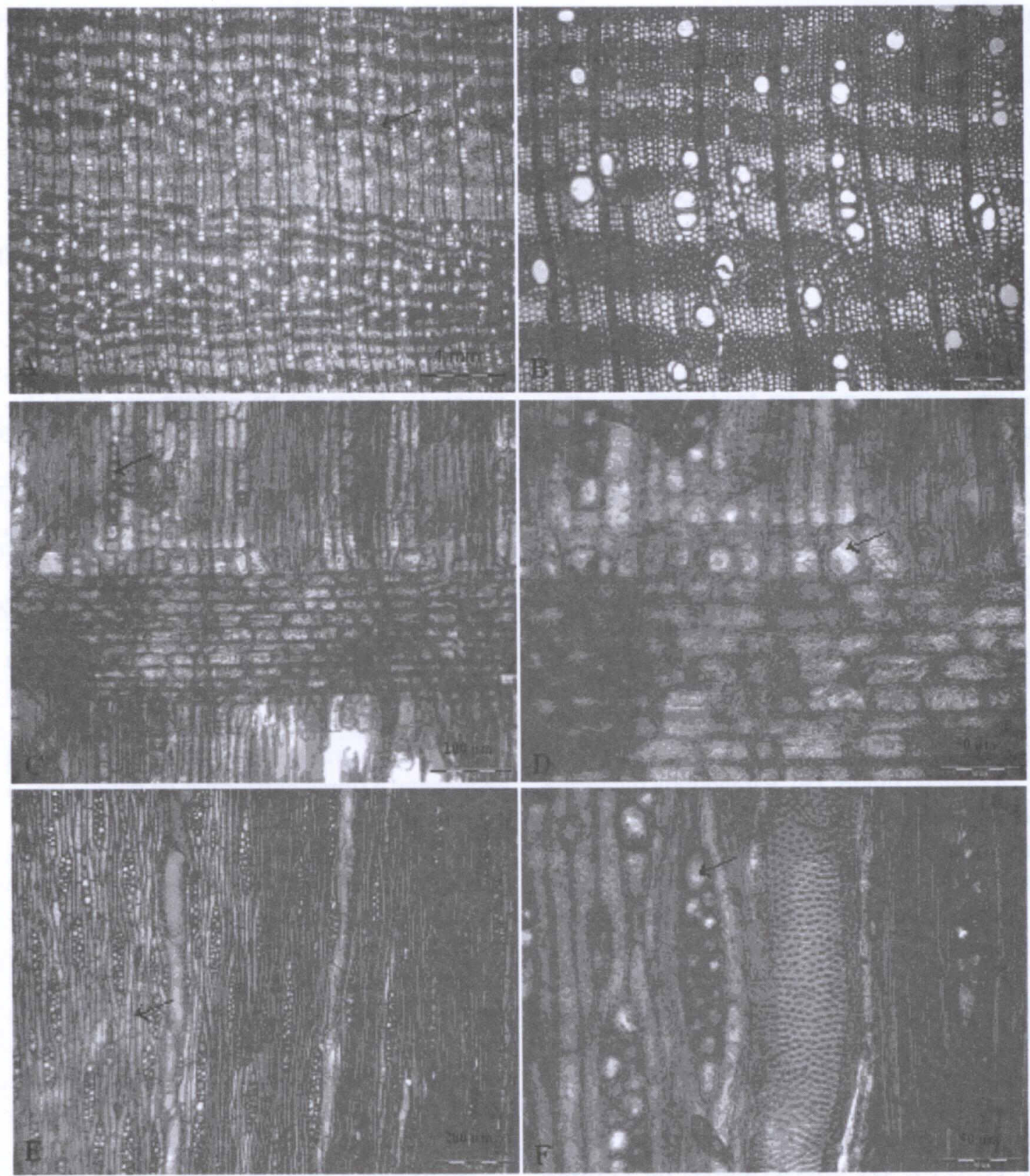

FIGURA 1 - Aspectos anatômicos da madeira de Callisthene inundata. A - Seção transversal, mostrando porosidade difusa, faixas concêntricas de fibras gelatinosas (seta), parênquima axial em faixas e limite de anel de crescimento pouco distinto. B - Mesma seção, em maior aumento, com poros solitários e em curtos múltiplos radiais, parênquima paratraqueal escasso, em faixas, e limite de anel de crescimento pouco distinto (cc). C - Parênquima axial com séries cristalíferas (seta) e raio heterogêneo com células procumbentes no corpo central e células eretas e/ou quadradas nas margens (seção longitudinal radial). D - Seção longitudinal radial, em maior aumento, mostrando células marginais de raios com cristais prismáticos (seta) e abundante conteúdo. E-Vista geral da seção longitudinal tangencial, com destaque para o parênquima axial abundante (seta) e raios uni e multisseriados, os últimos dos quais com margens de 1-2 células. F - Vasos com pontoações intervasculares alternas, circulares, e raios bisseriados com cristais (seta), em seção longitudinal tangencial. 
gada camada de fibras radialmente estreitas (Figura $1 \mathrm{~A}, \mathrm{~B})$.

Vasos: numerosos $(31 \pm 5,3(24-42)$ poros/ $\mathrm{mm}^{2}$ ), ocupando $13 \pm 3 \%$ do volume da madeira. Poros solitários e em múltiplos radiais de 23 (5), raros racemiformes, de seção circular $(59,2$ $\pm 12,1(37,5-77,5) \mu \mathrm{m})$ e paredes finas $(3,7 \pm$ $0,5(2,5-5) \mu \mathrm{m})$ (Figura 1A,B). Elementos vasculares pequenos $(314,2 \pm 60,7(190-430)$ $\mu \mathrm{m})$, com placas de perfuração simples, obliquas, e apêndices em uma ou em ambas as extremidades. Pontoações intervasculares pequenas $(4,5 \pm 0,5(4,1-5,1) \mu \mathrm{m})$, alternas, circulares, com abertura em fenda inclusa, ornamentada, por vezes coalescente (Figura 1F). Pontoações raio-vasculares com aréolas distintas, semelhantes às intervasculares, embora menores $(3,8 \pm 0,4(3,1-4,1) \mu \mathrm{m})$. Conteúdo, presente em vasos. Espessamentos espiralados, ausentes.

Parênquima axial: paratraqueal escasso e em largas faixas, com 3-7 (5) células de largura (Figura $1 \mathrm{~A}, \mathrm{~B})$, representando $28,7 \pm 4,8 \%$ do volume da madeira. Séries parenquimáticas de $337,4 \pm 63,5(212,5-437,5) \mu \mathrm{m}$ de altura, com $2-4$ células (Figura 1F). Parênquima fusiforme de 200,5 $\pm 24(137,5-242,5) \mu \mathrm{m}$ de altura. Cristais romboédricos, abundantes no parênquima axial.

Raios: numerosos $(11 \pm 1,9(9-14)$ raios/ $\mathrm{mm}$ ), com 1 - 3 células de largura, ocupando $17,2 \pm 2,2 \%$ do volume da madeira (Figura 1E,F). Os multisseriados, de 187,9 446 (105 292,5) $\mu \mathrm{m}$ de altura, com 7-16 (11) células; heterocelulares, reúnem células procumbentes, no corpo central multisseriado, e 1-2 fileiras de células marginais, quadradas e/ou eretas (Figura $1 \mathrm{C}, \mathrm{E}, \mathrm{F})$. Os unisseriados, de células procumbentes ou uma mistura de células quadradas e/ou eretas, medem $83,4 \pm 26,3$ (22,5 $132,5) \mu \mathrm{m}$ de altura, com $2-9$ células. Raios fusionados, raros. Raios agregados, células envolventes, células perfuradas e células de paredes disjuntas, ausentes. Cristais romboédricos, presentes, sobretudo, em células marginais. Conteúdos, abundantes.
Fibras: libriformes, de comprimento médio $(952,4 \pm 125,4(750-1270) \mu \mathrm{m})$ e $8,1 \pm 1,9(5$ $-11,2) \mu \mathrm{m}$ de largura, com paredes finas a espessas 4,3 $\pm 0,6(3,7-5,6) \mu \mathrm{m}$, ocupando 41,2 $\pm 2,3 \%$ do volume da madeira (Figura 1B). Fibras gelatinosas, em faixas concêntricas (Figura 1A,B). Fibras septadas, presentes. Espessamentos espiralados e traqueóides, ausentes.

Outros caracteres: variantes cambiais, tubos laticíferos e taniníferos, canais intercelulares, células oleíferas, células mucilaginosas, estratificação e máculas medulares, ausentes. Cristais romboédricos, abundantes em células marginais de raios e no parênquima axial (Figura 1D).

\section{ANÁLISE DA ESTRUTURA ANATÔMICA}

A maioria das características anatômicas do lenho de Callisthene inundata concorda com o mencionado por Record \& Hess (1942) para as Vochysiaceae: anéis de crescimento fracamente delimitados; poros solitários, numerosos e em curtos múltiplos radiais; placas de perfuração simples; pontoações intervasculares alternas, ornamentadas; raios curtos; parênquima axial abundante; e fibras libriformes de parede fina a espessa.

Além dos caracteres acima listados, distingue-se em Callisthene inundata a presença de poros pequenos, de elementos vasculares curtos, de pontoações intervasculares pequenas, de parênquima axial em largas faixas, de raios numerosos e heterogêneos, de fibras septadas de comprimento médio, com paredes finas a espessas, e de abundantes cristais romboédricos, aspectos reportados, igualmente, por Quirk (1980), para o gênero em questão.

No tocante à altura de raios, a espécie estudada apresenta valores abaixo do mencionado por Quirk (1980) para o gênero. Além disso, Callisthene inundata apresenta padrão radial de organização, aspecto não mencionado na literatura. Resta comentar que a presença de fibras libriformes e pontoações ornamentadas, características marcantes da família, são também confirmadas na espécie em estudo. 
REFERÊNCIAS BIBLIOGRÁFICAS

BARROS,C.F.; CALLADO, C.H.; CUNHA, M.; MARCON, M.L.F.; TAMAIO, N; MARQUETE, O.; COSTA, C. G. Madeiras da Mata Atlântica. Anatomia do lenho de espécies ocorrentes nos remanescentes florestais do estado do Rio de Janeiro, Brasil. Rio de Janeiro: Instituto de Pesquisas Jardim Botânico do Rio de Janeiro, 2003. 82 p.

BUENO, O. L.; NILSON, A. D.; MAGALHÃES, R. G. de. Callisthe inundata, nova espécie de Vochysiaceae e primeiro registro desta família no Estado do Rio Grande do Sul, Brasil. Iheringia, Série Botânica. Porto Alegre, n. 53, p. 101-116, 2000.

BURGER, L.M., RICHTER, H.G. Anatomia da Madeira. São Paulo: Ed. Nobel, 1991. 154 p.

DUJARDIN, E.P. Eine neue Holz-Zellulosenfaerbung. Mikrokosmos, n. 53, p. 94, 1964.

FREUND, H. Handbuch der Mikroskopie in der Technik. Frankfurt: Umsham Verlag, 1970.375 p.

MARCHIORI, J. N. C. Estudo anatômico do xilema secundário de algumas espécies dos gêneros Acacia e Mimosa, nativas no Estado do Rio Grande do Sul. 1980. 186f. Dissertação (Mestrado em Engenharia Florestal) - Universi- dade Federal do Paraná, Curitiba, 1980.

MATTOS, P.P.; TEIXEIRA, L.L.; SEITZ, R.A.; SALIS, M.S.; BOTOSSO, C.P. Anatomia de madeiras do Pantanal Mato-Grossense. Características microscópicas. Colombo: EMBRAPA Florestas: Corumbá: EMBRAPA Pantanal, 2003, $175 \mathrm{p}$.

METCALFE, C.R.; CHALK, L. Anatomy of the Dicotyledons. Oxford: Clarendon Press, 1972. p. 140-142.

QUIRK, J. T. Wood anatomy of the Vochysiaceae. IAWA Bulletin, v. 1, n. 4, p. 172-179, 1980.

RECORD, S.J.; HESS, R.W. Timbers of the New World. New Haven: Yale University Press, 1949. p. $550-552$.

SOBRAL, M.; JARENKOW, A. Flora arbórea e arborescente do Rio Grande do Sul. São Carlos: RiMa: Novo Ambiente, 2006. p. 156.

VIANNA, M. C. Vochysiaceae na Reserva Biológica de Poços das Antas, Silva Jardim, Rio de Janeiro, Brasil. Rodriguésia, Rio de Janeiro, v. 50, n. 3, p. 657-666, 2006.

WHEELER, E.A.; BAAS, P.; GASSON, P.E. IAWA list of microscopic features for hardwood identification. IAWA Bulletin, v.10, n. 3, p. 218359, 1989. 